\title{
MODIFICATION OF THE FISCHER INDOLE SYNTHESIS.
}

\author{
Guillermo Penieres $^{(1)}$, René Miranda ${ }^{(1)}$, José Garcia ${ }^{(1)}$, Juan Aceves ${ }^{(1)}$ and Francisco Delgado ${ }^{(2)}$ \\ (1) Facultad de Estudios Superiores Cuautitlán-UNAM, Sección de Química Orgánica, Campo 1, Av. 1 de Mayo \\ s/n, Cuautitlán Izcalli, Estado de México, C.P. 54740, México. \\ (2) Escuela Nacionai de Ciencias Bioiógicas-IPN, Depto. de Qulmica Orgánica, Prolongación Carpio y Plan de \\ Ayala, Casco de Santo Tomás, México D.F., C.P. 11340. Mexico.
}

\begin{abstract}
We describe a novel modification of the Fischer indole synthesis by using a natural clay and infrared irradiation.
\end{abstract}

\section{Introduction.}

Primarily, because of their pharmacological importance, heterocyclic compounds have been the subject of considerable synthetic activity during the past several years. For this reason, indoles have attracted much attention.

There are general methods described so far for the preparation of indoles involving different reagents. The Fischer reaction(1) is a common synthetic method used to obtain these compounds which involves heating a phenylhydrazone in presence of an acid catalyst, e.g.: $\mathrm{ZnCl}_{2}, \mathrm{BF}_{3}(1)_{r} \mathrm{PCl}_{3}$ (2) or polyphosphoric acid (3). The product yield and the success of the Fischer indole synthesis depends largely upon the choice of catalyst and the reaction conditions. The effectiveness of different materials such as hydrogen chloride, hydrochloric acid and varying proportions of $\mathrm{ZnCl}_{2}$ in catalyzing the indolization of acetone 4-chlorophenylhydrazone has been investigated (4). Another old modification, known as the Fischer-Arbuzow reaction (5), employs catalytic amounts of the Lewis acid.

On the other hand, a bentonitic earth (an aluminosilicate) has been used in several organic reactions as catalyst or reagent support, yielding good results (6-8). The physical and chemical properties of the clay were previously reported (9).

Continuing our research on the use of a natural bentonite as a Lewis acid catalyst, we have now developed a modified Fischer procedure using infrared energy as a convenient method to obtain indole derivatives.

\section{Experimental.}

In a general experiment $1 \mathrm{mmol}$ of phenylhydrazine and $1 \mathrm{mmol}$ of ketone were mixed with $4 \mathrm{~g}$ of clay and the mixture was IR irradiated with a commercial lamp of $250 \mathrm{~W}$ for $30 \mathrm{~min}$. Then, the product was extracted with ethanol, the clay was eliminated by filtering and the solvent evaporated under vacuum. The resulting compound was purified by recrystalization with a $1: 1$ ethanol-water mixture and spectroscopically identified by IR with a Perkin Elmer Model 283 spectrophotometer, 'H NMR using a Varian FT-200 spectrometer, and MS with a Hewlett Packard Model 5890.

\section{Results and Discussion.}

The results of several experiments are summarized in Table 1. 
Table 1.

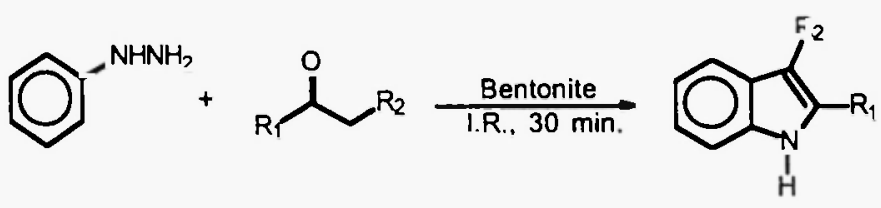

\begin{tabular}{|c|c|c|c|c|c|}
\hline$\overline{R_{1}}$ & $R_{8}$ & Yiold \% & Yield \% Rof. & $m p^{\circ} \mathrm{C}$ (obs) & $m p^{\circ} C_{(l i t)}$ \\
\hline $\mathrm{Me}$ & $\mathrm{H}$ & 85 & 65 (Ref. 12) & 61 & 61 \\
\hline$\overline{\mathrm{Me}}$ & $\mathrm{Me}$ & 80 & $\begin{array}{l}6 \text { (Ref. 13) } \\
81 \text { (Ref. 14) }\end{array}$ & $104-106$ & $95-100$ \\
\hline $\mathrm{Ph}$ & $\bar{H}$ & 40 & 60 (Ref. 15) & 188 & $188-189$ \\
\hline 2-Naphty & $H$ & 85 & - & $196^{\circ}$ & 196 \\
\hline \multicolumn{2}{|c|}{$-\left(\mathrm{CH}_{2}\right)_{3^{-}}$} & 60 & 49 (Ref. 15) & $107-108$ & $105-107$ \\
\hline \multicolumn{2}{|c|}{$-\left(\mathrm{CH}_{2}\right)_{4}-$} & 70 & 65 (Ref. 12) & 116 & 116 \\
\hline
\end{tabular}

"Yields of the purified products. Melting point is the same as the Sadtler's value.

As can be seen in Table 1, the yields obtained in this alternative synthetic route are good, some in a shorter time reaction, when they are compared with other results. Furthermore, in this work the reaction presented here only proceeds when the catalyst is employed. One of the experimental difficulties in the previously reported Fischer indole synthesis is the extreme temperature conditions that must be controlled in order'to obtain the appropriate results. Some researchers use very low temperatures (10), and others need high temperatures (11). In addition, other investigations use expensive reagents, as ruthenium catalyst (12), or non common materials (13). The present method is an efficient and easy synthetic route that makes use of an environmentally friendly catalyst natural clay. Our method only needs a readily available commercial infrared lamp and a natural clay catalyst for obtaining satisfactory results.

Acknowledgment. This work was supported by DGAPA-UNAM D0104593.

\section{References.}

1. Snyder H.R. and Smith C., J. Am. Chem. Soc. 1943, 65, 2452.

2. Baccolini G., Todesco P.E., J. Chem. Soc. Chem. Commun., 1981, 563.

3. Kissman H.M., Farnsworth D.W. and Witkop B., J. Am. Chem. Soc., 1952, 74, 3948

4. Stevens F.J. and Su H.C., J. Org. Chem., 1962, 27, 500

5. Arbusow A.E., Saizew J.A. and Kasumow A.J., Chem. Ber., 1935, 68, 1972.

6. Cabrera A., Rosas N., Márquez C. and Salmon M., Gazz. Chim. Ital., 1991, 121, 127.

7. Delgado F., Alvarez C., Garcia O., Penieres G. and Márquez C., Synth. Commun., 1991, $21,2347$.

8. Delgado F., Tamariz J., Zepeda G., Miranda R. and Garcia J., Synth. Commun., 1995, $25,753$.

9. Miranda R., Aceves J.M., Corona H., Dominguez J.M., and Salmón M., Synth. Commun; 1994, $24,727$.

10. Gassman P., Gilbert D. and van Bergen J., Chem. Commun., 1974, 201.

11. Kanaoka Y., Ban Y., Miyashita K., Irie K and Yonemitsu O., Chem. Pharm. Bull., 1966, 14, 934.

12. Tsuji Y., Huh K. and Watanabe Y., Tetrahedron Lett., 1986, 27, 377.

13. Bhattacharyya P. and Jash S., Ind. J. Chem., 1987, 1177.

\section{Received July 1, 1996}

